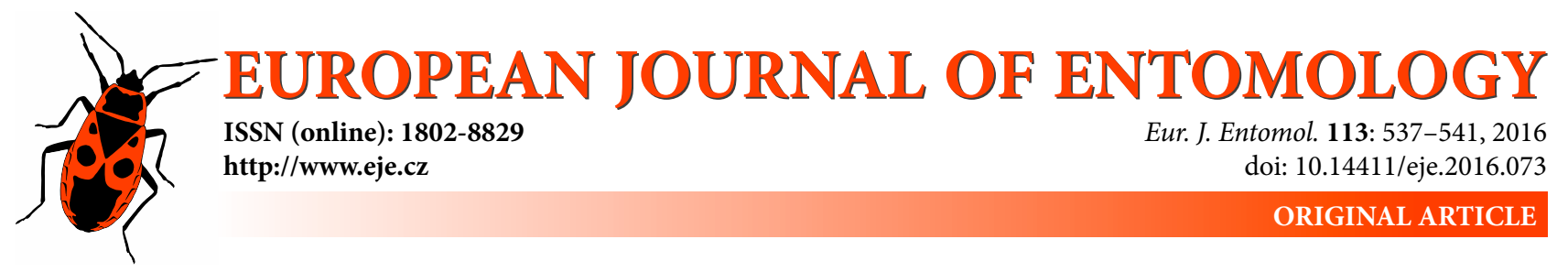

\title{
Cryoprotectant systems and cold tolerance of insects inhabiting central Yakutia (Russian Far East)
}

\author{
NAtAlia G. LI \\ Laboratory of Systematic and Ecology of Invertebrates, Institute for Biological Problems of Cryolithozone, Siberian Division \\ of Russian Academy of Sciences, Lenin avenue 41, Yakutsk, 677980, Republic Sakha (Yakutia), Russian Federation; \\ e-mail: li_natalia@mail.ru
}

Key words. Freeze-tolerance, ice nucleators, glycerol, cold hardiness potential, Siberian insects

Abstract. Strong tolerance of freezing is an important strategy for insects living in extremely cold regions. They produce highly effective cryoprotectant systems consisting of ice-nucleating proteins and polyols, which enables tolerable freezing of the body fluid. Therefore, the measurement of the concentrations of polyols and the activity of ice nucleators in the haemolymph is an essential tool for describing tolerance to ice formation in insects occurring in particularly cold places. This study evaluates three parameters: insect body supercooling point (SCP), haemolymph glycerol content and the profile of haemolymph ice nucleating activity that characterize the strategies of cold adaptation and cold hardiness in two previously unstudied beetles, Chrysolina graminis graminis L. and Galerucella nymphaea L., inhabiting Yakutia (Russian Far East, latitude $62^{\circ} \mathrm{N}$ ). The high SCP values, ice nucleating activity and survival of the chrysomelids after freezing indicate that both species are tolerant of freezing. According to the profiles of ice-nucleating activity, the haemolymph from $C$. graminis graminis is characterized by a higher nucleating potential than that from G. nymphaea. The glycerol level is also higher in C. graminis graminis. The results indicate that both species develop tolerance to low temperatures, but the cold hardiness potential of $C$. graminis graminis is greater than that of $G$. nymphaea. This was revealed by the survival test, in which beetles were frozen to a temperature of $-22^{\circ} \mathrm{C}$ for $30 \mathrm{~min} ; 86 \%$ of $\mathrm{C}$. graminis graminis and $72 \%$ of $G$. nymphaea survived the test. Thus, the freeze-tolerance of these beetles seems to be based on the production of an integrated cryoprotectant system, the quality of which apparently influences the range of their cold resistance.

\section{INTRODUCTION}

Insects inhabiting extremely cold regions are mainly able to survive the harsh climatic conditions there by being tolerant of freezing, which makes them different from insects inhabiting areas with mild climates, which have evolved mechanisms that enable them to avoid freezing (Miller, 1985; Duman et al., 1991; Sinclair et al., 2003; Zachariassen \& Kristiansen, 2003; Lee, 2010). Many of the insects inhabiting central Yakutia (Yakutsk, $62^{\circ}$ latitude, $130^{\circ}$ longitude) use the same strategy $(\mathrm{Li}, 2016)$. This region is characterized by an average annual temperature of approximately $-11^{\circ} \mathrm{C}$ (absolute minimum temperature $-64.4^{\circ} \mathrm{C}$; Gavrilova, 1998). The thickness of snow cover is generally only $250 \mathrm{~mm}$ or even less. Therefore, to survive in such conditions, insects mostly develop a strong tolerance of freezing $(\mathrm{Li}, 2014,2016)$. Despite the fact that the lowest temperature recorded in this region is $-64.4^{\circ} \mathrm{C}$, many of the insects seem capable of withstanding much lower temperatures, such as $-85^{\circ} \mathrm{C}$ and even lower temperatures, which demonstrates the significant adaptation potential of these insects. Studies on Siberian insects, such as Aporia crataegi L. (Lepidoptera: Pieridae) and others, have demonstrated that their cold hardiness potential is associated with the production of an effective cryoprotectant system consisting of polyols and ice-nucleating proteins (INPs) (Li, 2011, 2012). INPs in the haemolymph seem to be an essential part of their tolerance of freezing conditions. Like the INPs in Tipula trivittata (Yeng et al., 1991), those in Siberian insects apparently have the ability to aggregate, forming a template around which an ice crystal can form and grow to become large enough to ensure freezing at subzero temperatures $(\mathrm{Li}, 2012)$. In this way it is likely that ice nucleating agents initiate safe and controlled ice formation in the extracellular environment at subzero temperatures before ice can form inside cells, which is fatal for many insects (Zachariassen, 1985).

It is known that INPs differ from one another in terms of their ice nucleating potential, which depends on the number and quality of the aggregates that they form (Zachariassen \& Hammel, 1988). Quantitatively, ice-nucleating potential can be estimated by determining the effect of diluting the insect haemolymph on ice-nucleating activity (INA) (Zacharissen et al., 1982). By applying this approach to the study of the cold hardiness of Siberian insects, it was shown that during winter, the haemolymph of Aporia crataegi caterpillars inhabiting Yakutia can be 
diluted by a factor of $10^{6}$ without any significant reduction in its ice nucleating activity (Li, 2012). However, acclimatization to warm conditions induced dramatic changes in the physicochemical conditions in the haemolymph, resulting in a drop in the ice nucleating potential and a decline in the glycerol concentration over the entire period of acclimation. Analyses of the profile of ice nucleating activity showed that qualitative changes occurred in the structure of INPs that were linked to a decrease in the glycerol content during acclimatization. Therefore, it was hypothesized that the mechanism by which glycerol protects the body of A. crataegi from low temperature damage mainly includes a non-colligative effect. Glycerol in the hemolymph seems to facilitate the formation of large aggregates of INPs with high nucleating capacity as a consequence of which ice nucleating activity insignificantly depends on haemolymph dilution. The utilization of glycerol during acclimatization to warm conditions perhaps leads to the de-aggregation of INA complexes, causing a loss in the cold hardiness potential of $A$. crataegi (Li, 2012).

The temperature parameters primarily used for describing cold adaptation and cold hardiness are the super cooling point (SCP), proportional lethal temperature (LTx) and lower lethal temperature (LLT) (Sinclair et al., 2015). The problem could be that these parameters are not suitable for "visualizing" the physicochemical conditions in the haemolymph of insects at certain stages in their cold hardiness. In this respect, the use of three parameters, SCP, the profile of ice-nucleating activity and the glycerol concentration, could be an additional option for assessing insect resistance to low temperatures. The aim of this study is to determine, using the approach described, the type of cold adaptation strategy and cold hardiness potential of two yet unstudied species belonging to the family Chrysomelidae (Coleoptera), Chrysolina graminis graminis L. and Galerucella nymphaeae L., inhabiting central Yakutia. The use of several parameters to describe the cold hardiness of these tiny Siberian species will hopefully contribute to a more accurate study of their cold adaptation and help determine if the approaches presented in previous studies could be universally applied. Using a variety of approaches for evaluating insect cold hardiness certainly contributes to a deeper understanding of the mechanism of their resistance to cold.

\section{MATERIALS AND METHODS}

\section{Insects}

The beetles are too difficult to find in their natural habitat in a cold winter; therefore, they were collected from their natural habitats in the vicinity of Yakutsk in late autumn 2014. They were then kept in a laboratory incubator, the temperature of which was slowly changed from $0 \ldots-1{ }^{\circ} \mathrm{C}$ (in September) to $-6^{\circ} \mathrm{C}$ (in January) and $+4^{\circ} \mathrm{C}$ (in May). The incubator was placed in a room with natural lighting. A small glass window was inset in the door of the incubator and only natural light penetrated inside the incubator. The beetles were kept inside a Styrofoam box with melting ice as described by Kristiansen (Kristiansen at al., 2009) when the temperatures inside the incubator were $0 \ldots-2^{\circ} \mathrm{C}$. Because of the presence of water drops inside the box, the air was always saturated with water vapour. When the temperatures inside were above $0^{\circ} \mathrm{C}$, wet filter paper strips were fixed to side walls of the incubator, to ensure optimal humidity.

\section{Preparation of haemolymph samples}

Haemolymph samples were obtained as described by Zachariassen (Zachariassen et al., 1982). A beetle leg was excised and the exuding haemolymph was drawn into a thin glass capillary tube by means of capillary action. Due to the small body size of the insects, the haemolymph from 2-3 beetles was collected in each glass capillary tube. Before measuring, the capillary tubes were centrifuged at $5000 \mathrm{rpm}$ for $5 \mathrm{~min}$ in a microcentrifuge (CM-50) to move the body fluid sample down to the closed end of the tube. To avoid evaporation from the sample as well as oxidative processes within the haemolymph, a droplet of mineral oil was added to each capillary tube and the open end of the capillary tube was then sealed by melting in a flame.

\section{SCP}

The SCP of the beetles was measured using a thin copper-constantan thermocouple placed in close contact with the dry body surface as described by Kristiansen (Kristiansen et al., 2009). A layer of thin adhesive tape was wrapped around the thermocouple probe to prevent it from scratching the surface of the beetles and thus affecting the SCP. The thermocouple was connected directly to a line recorder (INSEIS L120E, Germany) and the temperature recorded every $10 \mathrm{~s}$. The beetles with a thermocouple attached were cooled inside a Binder climatic chamber (TC-G-180, Tuttlingen, Germany) at a rate of approximately $1^{\circ} \mathrm{C} / \mathrm{min}$. The initiation of freezing was detected as a sudden temperature increase due to the release of the heat of fusion when the body water froze, and the lowest temperature recorded prior to the temperature increase was taken as the SCP.

\section{Glycerol concentration and ice nucleating activity}

The glycerol concentration and ice-nucleating activity was determined before the insects were frozen. The glycerol concentration was measured enzymatically using $4 \mu \mathrm{l}$ samples of insect haemolymph and a Sigma F6428 Free Glycerol Reagent Kit.

The principle of the haemolymph ice nucleating activity test is based on the observation that small samples of distilled water can easily supercool to $-18^{\circ} \mathrm{C}$, whereas samples containing potent INAs will freeze at a few degrees below zero. The nucleator activity in insect haemolymph has been well-investigated by Zachariassen et al. (1982), and their method was used without substantial modifications. Each sample contained $4.5 \mu \mathrm{L}$ of $0.9 \%$ $\mathrm{NaCl}$ prepared with highly purified water (Applichem, Germany) in a thin glass capillary tube, which was isolated from the air by a layer of mineral oil. One-half microliter of the haemolymph sample prepared as described above was added by means of a microsyringe through the oil layer in each glass capillary tube containing the $\mathrm{NaCl}$ solution. The SCPs were measured by attaching three samples by means of adhesive tape to a highly sensitive thermocouple, which was connected to a potentiometric line recorder, which recorded the temperature to an accuracy of $\pm 0.15^{\circ} \mathrm{C}$. Evidence of freezing was indicated by a sudden increase in temperature linked to the release of the heat of fusion when the water froze. The specific ice nucleating activity was determined by the isovolumetric technique of sample dilution in which each sample was diluted by the same factor from the same stock solution (Zachariassen et al., 1982). These measurements were made on the 20-22th December 2014.

\section{Determination of cold hardiness}

In their natural habitat, C. graminis graminis and G. nymphaea are tolerant of low ambient temperatures. However, if the beetles 


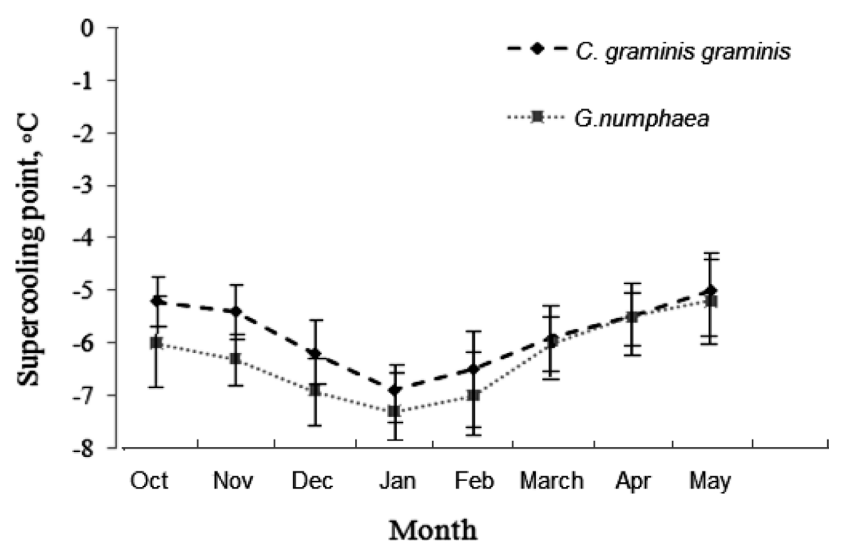

Fig. 1. Seasonal variation in whole body supercooling points of $C$. graminis graminis and G. nymphaea.

are removed from their overwintering places, they become sensitive to freezing at such temperatures (pers. observ.). Therefore, in this study, the test for estimating the cold hardiness of the beetles was based on the percentage of beetles that are tolerant of freezing at a moderately low temperature: $-22^{\circ} \mathrm{C}$ for $30 \mathrm{~min}$ at a cooling rate of approximately $1{ }^{\circ} \mathrm{C} / \mathrm{min}$. The super cooling point was measured as described above. After freezing, the beetles were warmed at room temperature and checked for their capacity for active movement for at least $1 \mathrm{~h}$. In total, 10 specimens of each species were used in this experiment.

\section{Water content}

To determine their water content, the beetles were dried to a constant weight at $60^{\circ} \mathrm{C}$ in an oven (TM-80, Russia). The loss in weight was determined by weighing the animals before and after desiccation using a Mettler AC 88 balance. The loss of body mass was taken as due to water loss, which was measured to an accuracy of $\pm 0.1 \mathrm{mg}$.

\section{Statistical methods}

In general, the reproducibility of the data related to the determination of ice-nucleating activity in the samples of diluted haemolymph was good. The means \pm standard error (SD) for the ice nucleating activity at each step in the haemolymph dilution were compared using ANOVA/Tukey's test (statistical package Statistica v. 6.0). The mean insect body SCP, body weight, water content and glycerol concentration $\pm \mathrm{SD}$ were analyzed using the same statistical method. The differences were considered to be statistically significant at $\mathrm{p} \leq 0.05$.

\section{RESULTS AND DISCUSSION}

The overwintering site of $C$. graminis graminis is unknown, while $G$. nymphaea hibernates in soil under snow cover. These chrysomelids are small and contain a significant amount of water in their bodies (Table 1), which is a common feature of many freeze-tolerant insects, with rare exceptions (Zachariassen et al., 2008; Li, 2015). Accord-

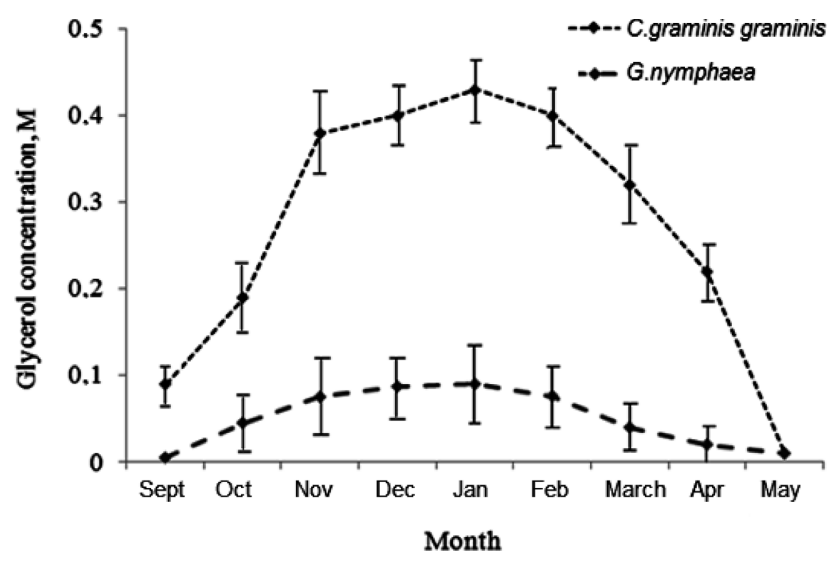

Fig. 2. Seasonal change in glycerol content of the hemolymph of C. graminis graminis and G. nymphaea.

ing to previous studies, ice-nucleating agents in the haemolymph convert water from liquid to ice, thus keeping the body fluids of freeze-tolerant insects in vapour pressure equilibrium with ice (Zachariassen et al., 2008).

As shown in Fig. 1, the SCP decreased during cold hardening in both species and started to increase as soon as spring-like temperatures were experienced. The glycerol level also changed depending on the temperature regime and was highest in January, which is when the lowest values of the beetles' SCPs were recorded (Fig. 2). The glycerol content was expected to be higher in both species and more comparable with those of previously examined Yakutian insects: the beetles seem to produce less glycerol when acclimated in the laboratory than under natural conditions (Table 2). The experience of spring-like temperatures caused a decrease in haemolymph glycerol and was accompanied by an increase in the haemolymph SCP. Given that the beetles have an SCP within a high subzero temperature range, the haemolymph is likely to contain endogenous INAs (Table 1). The beetles were frozen and then warmed up to room temperature. During these tests, the beetles clearly demonstrated their ability to move and regain coordination within three hours of the start of the observation on the recovery. This finding reveals they are freeze-tolerant.

Fig. 3 shows that the haemolymph of $C$. graminis graminis can be diluted by a factor of up to $10^{4}$ without any significant reduction in ice nucleating activity. Within this concentration range, the nucleating activity forms a plateau at which it is not significantly affected by variation in the nucleator level. In G. nymphaea, the ice nucleating activity was dramatically reduced at a haemolymph dilution factor of $10^{2}$. According to Fig. 3, the profiles of ice

Table 1. Overwintering habitat, type of cold adaptation and physiological parameters of the haemolymph of C. graminis graminis and G. nymphaea.

\begin{tabular}{lccccccc}
\hline Insect & $\begin{array}{c}\text { Overwintering } \\
\text { habitat }\end{array}$ & $\begin{array}{c}\text { Body weight } \\
(\mathrm{mg})\end{array}$ & $\begin{array}{c}\text { Water content } \\
(\%)\end{array}$ & $\begin{array}{c}\mathrm{SCP} \\
\left({ }^{\circ} \mathrm{C}\right)\end{array}$ & $\begin{array}{c}0,9 \% \mathrm{NaCl}+ \\
\text { hemolymph }\end{array}$ & $\begin{array}{c}\text { Glycerol } \\
\text { concentration, M }\end{array}$ & $\begin{array}{c}\text { Type of cold } \\
\text { adaptation }\end{array}$ \\
\hline Chrysolina graminis & Unknown & $\begin{array}{c}106 \pm 2.0 \\
(\mathrm{n}=4)\end{array}$ & $\begin{array}{c}70.7 \pm 2.3 \\
(\mathrm{n}=3)\end{array}$ & $\begin{array}{c}-6.9 \pm 0.33 \\
(\mathrm{n}=5)\end{array}$ & $\begin{array}{c}-6.1 \pm 0.25 \\
(\mathrm{n}=4)\end{array}$ & $\begin{array}{c}0.4 \pm 0.12 \\
(\mathrm{n}=3)\end{array}$ & FT \\
graminis L. & & $\begin{array}{c}8 \pm 1.4 \\
\text { Galerucella nymphaea } \mathrm{L} .\end{array}$ & $\begin{array}{c}65.9 \pm 1.8 \\
(\mathrm{n}=3)\end{array}$ & $\begin{array}{c}-7.3 \pm 0.54 \\
(\mathrm{n}=5)\end{array}$ & $\begin{array}{c}-7.5 \pm 0.34 \\
(\mathrm{n}=4)\end{array}$ & $\begin{array}{c}0.087 \pm 0.073 \\
(\mathrm{n}=3)\end{array}$ & FT \\
& under snow & $(\mathrm{n}=4)$ & & & & &
\end{tabular}

FT - freeze-tolerance. Values in brackets indicate the number of observations. 


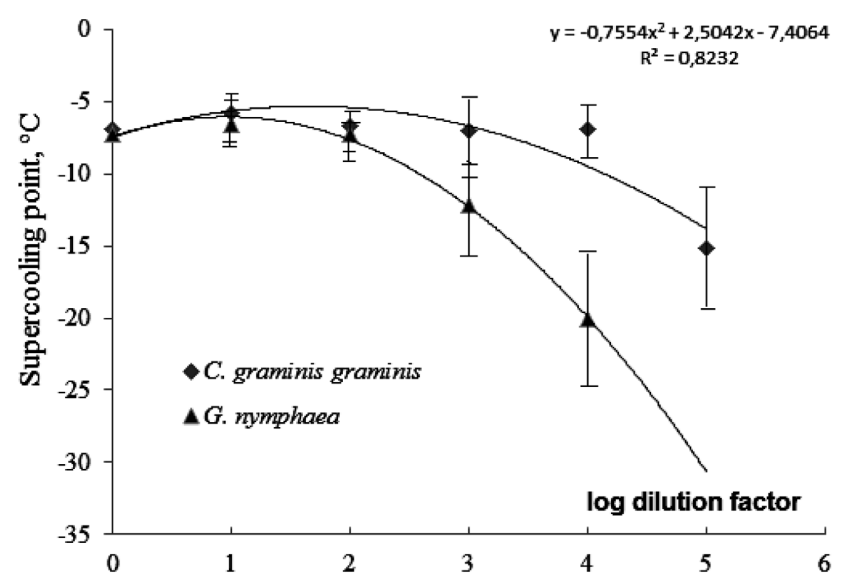

Fig. 3. The profiles of ice nucleating activity of $0.5 \mu \mathrm{L}$ samples of the hemolymph of $C$. graminis graminis and G. nymphaea, diluted by factor 10 by adding $4.5 \mu \mathrm{L}$ of $0,9 \% \mathrm{NaCl}$ solution, and expressed as a the dilution factor (each point is the mean value for four samples collected from several specimens \pm SD at the same time).

nucleating activity are characterized by the widest plateau occurring in winter, and this was associated with the ability of the beetles to survive at $-22^{\circ} \mathrm{C}$ for $30 \mathrm{~min} ; 86 \%$ of the C. graminis graminis and $72 \%$ of the G. nymphaea survived exposure to this temperature. Thus, the haemolymph dilution factor at which the ice nucleating activity started to decrease significantly was considered to be the critical dilution factor. Because ice nucleators differ in their ice nucleating capacity, the critical dilution factor seems to be a specific feature of ice nucleators in freeze-tolerant insects (Zachariassen et al., 1982). Although this parameter is an inexact measure of specific ice-nucleating activity, I believe it can be used until a more accurate parameter is determined in the future (Table 2).

Based on the physicochemical conditions in the insect's haemolymph, one might suggest that the difference in the profiles of ice-nucleating activity between the species seems to be associated with a difference in the haemolymph glycerol level (Table 2). A glycerol level of $0.4 \mathrm{M}$ in C. graminis graminis haemolymph is apparently more favourable for the formation of the ice nucleating capacity of the nucleators, with a surface that is more suitable for nucleation, than that of the $0.087 \mathrm{M}$ glycerol in the G. nymphaea haemolymph and $C$. graminis graminis, therefore seems to be a more cold-resistant insect than G. nymphaea. This pattern is consistent with those reported for other Yakutian species (Li, 2011, 2012). The data in Table 2 show that the polyol concentrations and ice nucleating activity in chrysomelid haemolymph influence their cold hardiness. The harsh winter conditions in central Yakutia are determined by fairly thin snow cover and a prolonged period of temperatures ranging from -50 to $-55^{\circ} \mathrm{C}$. Therefore, the distribution of these beetles in this region demonstrates that both of these species are adapted to these conditions and are potentially resistant to the very low winter temperatures occurring in this area.

Thus, the results of the present study indicate that there is a relationship between the cold hardiness of Siberian beetles, INA activity and glycerol content. Based on this evidence, I hypothesize that glycerol and ice-nucleating proteins are an integrated part of the cryoprotectant system of these chrysomelids, which enables them to survive very low ambient temperatures. In this system, the structure of the INAs seems to depend on the glycerol (polyols) level in the haemolymph, which greatly affects their cold tolerance. It is clear that additional research is needed to shed more light on the functions of glycerol in freeze-tolerant insects.

ACKNOWLEDGEMENTS. I would like to acknowledge my colleagues, N. Vinokurov, A. Popov and S. Nogovitsina for help with collecting, transportation and identification of the beetles used in this research. I wish also to thank both of the reviewers for valuable advice on improving the content.

\section{REFERENCES}

Duman J.G., Wu D.W., Xu L., Tursman D. \& Olsen M. 1991: Adaptations of insects to subzero temperature. - Quart. Rev. Biol. 66: 387-410.

Gavrilova M.K. 1998: The Climates of Cold Regions of Earth. Siberian Division of Russian Academy of Sciences, Yakutsk, $234 \mathrm{pp}$.

Kristiansen E., Li N.G., Averensky A.I. \& Zachariassen K.E. 2009: The Siberian timberman Acanthocinus aedilis: a freezetolerant beetle with low supercooling points. - J. Comp. Physiol. (B) 179: 563-568.

LeE R.E. 2010: A primer on insect cold-tolerance. In Delinger D.I. \& Lee R.E. (eds): Insects at Low Temperatures. Cambridge University Press, UK, pp. 3-35.

Li N.G. 2011: Ice nucleating activity of the Upis ceramboides hemolymph inhabiting central Yakutia. - Probl. Cryobiol. 21: 34-46.

Li N.G. 2012: Relationships between cold hardiness, and ice nucleating activity, glycerol and protein contents in the hemolymph of caterpillars, Aporia crataegi L. - Cryoletters 33: 134-142.

Li N.G. 2014: Physiological Mechanisms of Adaptation of Insects to the Dry and Cold Climate of Yakutia. PhD thesis, Kazan Federal University, Kazan, $203 \mathrm{pp}$.

Li N.G. 2015: Water balance of freeze-tolerant insect larvae inhabiting arid areas in Eastern Siberia (Yakutia, Russia) - Euroas. Entomol. J. 14: 37-41.

Li N.G. 2016: Strong tolerance to freezing is a major survival strategy in insects inhabiting central Yakutia (Sakha Republic,

Table 2. Some physiological properties of overwintering chrysomelids from central Yakutia.

\begin{tabular}{|c|c|c|c|c|}
\hline \multirow{2}{*}{ Insect } & \multicolumn{3}{|c|}{ Physiological parameters of the insect's haemolymph } & \multirow{2}{*}{ Survival at $-22^{\circ} \mathrm{C}, \%^{\mathrm{b}}$} \\
\hline & $\operatorname{SCP}\left({ }^{\circ} \mathrm{C}\right)$ & Glycerol content, $\mathrm{M}$ & Critical dilution factor ${ }^{a}, \log$ & \\
\hline C. graminis graminis (adult) $(n=4)$ & $-6.9 \pm 0.33$ & $0.4 \pm 0.12$ & 4 & 86 \\
\hline G. nymphae (adult) $(n=5)$ & $-7.3 \pm 0.14$ & $0.087 \pm 0.073$ & 2 & 72 \\
\hline
\end{tabular}

a Specific ice-nucleating activity expressed as a critical dilution factor at which activity of ice nucleators starts to decrease dramatically.

${ }^{b}$ Data on survival are for 10 specimens of each species. 
Russia), the coldest region in earth. - Cryobiology 73: 221225.

MiLLER K. 1985: Cold hardiness in invertebrate poikiloterms. Comp. Biochem. Physiol. (A) 73: 595-605.

Sinclair B.J., Addo-Bediako A. \& Chown S.L. 2003: Climatic variability and the evolution of insect freeze tolerance. - Biol. Rev. 78: 181-195.

Sinclair B.J., Alvarado L.E.C. \& Ferguson L.V. 2015: An invitation to measure insect cold tolerance: Methods, approaches, and workflow. - J. Therm. Biol. 53: 180-197.

Yeng K.L., Wolf E.E. \& Duman J.G. 1991: A scanning tunneling microscopy study of an insect lipoprotein ice nucleator. $-J$. Vacuum Sci. Tech. 9: 1197-1201.

ZaChARIASSEN K.E. 1985: Physiology of cold tolerance in insects. —Physiol. Rev. 65: 799-832.
Zachariassen K.E. \& Hammel H.T. 1988: The effect of ice-nucleating agents on ice-nucleating activity. - Cryobiology 25: 143-147.

ZaChariassen K.E. \& KristianSEN E. 2003: What determines the strategy of cold-hardiness? - Acta Soc. Zool. Bohem. 67: $51-58$.

Zachariassen K.E., Baust J.G. \& Lee R.J. 1982: A method for quantitative determination of ice nucleating agents in insect hemolymph. - Cryobiology 19: 180-184.

Zachariassen K.E., Li N.G., Laugsand A.E., Kristiansen E. \& Pedersen S.A. 2008: Is the strategy for cold hardiness in insects determined by their water balance? A study on two closely related families of beetles: Cerambycidae and Chrysomelidae. J. Comp. Physiol. (B) 178: 977-984.

Received September 12, 2016; revised and accepted October 7, 2016 Published online November 2, 2016 